\title{
The effect of balanced versus unbalanced football small-sided games on decision-making in youth football players \\ El efecto de los juegos reducidos de fútbol equilibrado versus desequilibrado en la toma de decisiones de los jugadores de fútbol Juvenil \\ *Honorato Sousa; *Élvio Rúbio Gouveia; **Adilson Marques; ***Hugo Sarmento; *Helder Lopes; ****Andreas Ihle \\ *University of Madeira (Portugal); **Faculdade de Motricidade Humana (Portugal); ***University of Coimbra (Portugal); ****University of Geneva (Switzerland)
}

\begin{abstract}
Decision-making (DM) is an important ability targeted in the formation of young football players that can improve by using small-sided games (SSGs). The main purpose of this study was to assess players' DM in different balanced and unbalanced SSG formats keeping the play area constant. The sample was composed of 10 field players plus 2 goalkeepers (13.55 \pm 0.51 years). This study consisted of 3 sessions, one day for each session, with an interval of 48 hours apart between sessions. Three different SSG formats (4vs.4; 4vs.5; 4vs.6), in a play area of 40x30 meters, were selected. The outcome was the decision-making index (DMI), assessed with the Game Performance Assessment Instrument (GPAI). Results showed that on two of the three days, there were statistical differences in DMI across the three different SSG formats. In the 4vs. 6 format a higher median score than in the 4vs. 4 format was recorded on day $2(U=13.0, \mathrm{z}=-2.34, p=.025, \mathrm{r}=.57)$ and day $3(\mathrm{U}=5.50$, $\mathrm{z}=-2.98, \mathrm{p}=.003, \mathrm{r}=.72$ ). In conclusion, the use of unbalanced SSG formats in the training may benefit DM development, and therefore may constitute an important factor to be considered in the formation of young football players.
\end{abstract}

Keywords: Decision-making; small-sided games; balanced; unbalanced.

Resumen. La toma de decisiones (TD) es una habilidad importante dirigida a la formación de jugadores de fútbol jóvenes que puede mejorar mediante el uso de juegos reducidos (JR). El objetivo principal de este estudio fue evaluar el TD de los jugadores en diferentes formatos en JR equilibrados y desequilibrados manteniendo constante el área de juego. La muestra estuvo compuesta por 10 jugadores de campo más 2 porteros (13,55 \pm 0,51 años). Este estudio consistió en 3 sesiones, un día por cada sesión, con un intervalo de 48 horas entre sesiones. Se seleccionaron tres formatos diferentes (4vs.4; 4vs.5; 4vs.6), en un área de juego de 40×30 metros. El resultado fue el índice de toma de decisiones (ITD), evaluado con el Game Performance Assessment Instrument (GPAI). Los resultados mostraron que, en dos de los tres días, hubo diferencias estadísticas en ITD en los tres diferentes formatos. En el formato 4vs.6 se registró una puntuación media más alta que en el formato 4vs.4 el día $2(\mathrm{U}=13.0, \mathrm{z}=-2.34, \mathrm{p}=.025, \mathrm{r}=.57)$ y el día $3(\mathrm{U}=5.50, \mathrm{z}=-2,98, \mathrm{p}=.003, \mathrm{r}=.72)$. En conclusión, el uso de JR desequilibrados en el entrenamiento puede beneficiar el desarrollo de la TD y, por tanto, puede constituir un factor importante a considerar en la formación de futbolistas jóvenes.

Palabras clave: Toma de decisiones; juegos reducidos; equilibrados; desequilibrados.(Endnotes)

\section{Introduction}

The evolution and development of new training methodologies are crucial for the progress of collective sports since it allows the optimization of the team performance and development of each player. The literature has shown for some time that future research should emphasize changes in basic knowledge of the game, motor patterns, and, above all, the behaviors and skills of the game (Turner \& Martinek, 1995; French \& McPherson, 2004). It is also underlined that the priority

Fecha recepción: 26-02-21. Fecha de aceptación: 23-05-21

Honorato José Sousa

honoratosousa@hotmail.com in approaching and training the tactical-technical component should fall on the use of small-sided games (SSGs) instead of using analytical situations (Davids et al., 2013; Clemente, Mendes, \& Rocha, 2012; Grehaigne, Richard, \& Griffin, 2012). There is unequivocally the potential of SSGs for the development of the game skills. Besides, the game action itself is more adjusted to natural interests and motivations of the players since it combines the development of the tacticaltechnical component through real game contexts (HillHaas et al., 2011; Dellal et al., 2012; Davids et al., 2013).

Although there is evidence about the contribution of SSGs to the development of the tactical-technical component of the game, and its regular use by coaches 
(Clemente et al., 2012; Michailidis, 2013; Sgró et al., 2018; Torreblanca-Martínez et. al., 2018; Menegassi et al., 2020), a single SSG format does not answer to all requirements needed. It is important to underline that the use of SSGs does not mean that the objectives for which they were conceived are being achieved or whether the formats used are the most adjusted to the intended training context. More studies on the topic are required to better understand the impact of different game constraints on the needs of players.

For some time now, the literature has not only recommended that the different formats of SSGs and the different variables that compose them await a scientific demonstration on their effectiveness, it also advises that future studies should analyze changes in basic knowledge, in motor patterns, and, above all, in the behaviors and skills of playing associated with DM in young practitioners (French \& McPherson, 2004; Baldi et al., 2016). Studies like Ric et al. (2016) and Canton et al. (2019) indicate that no research has assessed the effects of temporary numerical imbalances on the team's exploratory behavior, and DM is one of the crucial factors in that particularly game component.

DM, identified as an important ability for successful performance in team sports, consists of the use of information generated by the game situation, combined with the player's capacity to apply his/her knowledge about that same context to plan, select, and execute an action or a set of functional actions among a large number of possible actions, aimed at fulfilling the objective of the game (Williams, 2013; Araújo, 2019). The study of DM is not a normative and linear process, as not only DM but also the factors that influence it (biological maturation, level of practice or skill and knowledge of the game, among others), interact with the different specificities of the diversified and often unpredictable game contexts. DM therefore is an important ability targeted in the formation of young football players, as it assumes an ever-greater preponderance, being an active and continuous process in the search for information to play, where the moment requires immediate action, always being conditioned by what the contexts allow to do, suffering influence from colleagues, opponents, time pressure, among others (Passos et al., 2008; Mills et al., 2012).

DM training is based on the theoretical principles of ecological dynamics, with the manipulation of the task, context, and individual restriction factors, giving rise to the creation of dynamic and real game situations, whether through manipulation of the number of players, the effective playing space, the imposition or alteration of rules, or the conditioning or restrictions of the game action (Araújo et al., 2009; Sarmento et al., 2018). Some studies confirmed that the restriction of tasks and the manipulation of the conditions of practice are fundamental aspects for the tactical-technical development (Correia et al., 2012; Correia et al., 2013; Travassos et al., 2012), however, so far only few studies have analyzed the relationship between specific SSG formats and DM.

Therefore, this study aimed to investigate behaviors associated with the performance of the game, especially those of a tactical nature, estimating the DMI of the players in different balanced and unbalanced SSG formats (4vs.4; 4vs.5; 4vs.6), in a play area with 40x30 meters.

\section{Material and Methods}

\section{Sample}

The sample was composed of 10 field players plus 2 goalkeepers ( $13.55 \pm 0.51$ years). All members belonged to the same team, with 3 training sessions of 75 minutes per week, and the competitive moment at the end of the week. All players were federated for at least 3 years in the Madeira Football Association.

The players were informed about the objectives of the research and its requirements as well as the potential benefits and risks. Participation was voluntary. Informed consent was signed by the parents or legal guardians and the players gave their verbal assent. All procedures followed the guidelines stated in the Declaration of Helsinki and were approved by the Scientific Board of the Department of Physical Education and Sports of the University of Madeira.

\section{Procedures}

This study consisted of 3 sessions, one day for each session, with an interval of 48 hours between sessions. The main reason for choosing these 3 assessment days was to have more accurate conclusions from the data collected. 3 different SSG formats were selected, with a duration of 5 minutes of practice and another 5 minutes of rest (passive and hydrated) between each performance. The order of the exercises was randomized on the first day of the study (from 1 to 3), following the same order on the remaining days to be able to study the stability of the results. The complete description of each SSG format and the random order are presented in Table I. The activities began at 10:30 am and ended at 12 pm every day, including warm-up, game situations, recovering time, cooldown, and stretching. Each session 
and game format were filmed using two GOPRO 4, that recorded the game action in the laterality and depth of the game space. The warm-up lasted 15 minutes, starting with a general mobilization and musculoskeletal activation, ending with a ball possession situation and active stretching. The infrastructures where the study took place were located in Funchal, Madeira Portugal. The field, an uncovered synthetic grass, was located at an altitude of 292 meters above sea level, with the dimensions of 100 meters long and 64 meters wide.

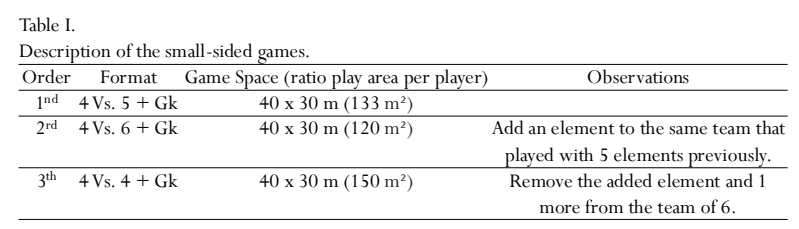

The goals used were those of the variant of football 7, with 6 meters in length and 2 meters in height. Replacements of the ball in the game were made by hand-throwing when the ball came out of the sidelines. In the case of goal occurred, the goalkeeper as the freedom to follow with the controlled ball by hand or feet unopposed. In the case of a corner, the ball was set by the goalkeeper of the team that would have the possession of the ball. The purpose was to reduce breaks or stops at the pace of the game.

The team's coach helped in the constitution of the teams, trying to strike a balance between commonly played game functions and individual quality, also taking into account the permanent numerical inferiority of a team over 2 of 3 formats. No request was made for the players to occupy specific functions, only advised to try to maintain an organized structure, taking into account the necessity to defend one goal and attack another. No instructive feedback was provided, just the constant call to keep up the pace and seek to perform the actions with the commitment. The study took place in the middle of the season, during a period without official competition.

A pilot study was performed at the same facilities before the main study, to validate the assessment protocols and the experimental game situations (see below for further details).

\section{Outcome measures}

The outcome was the DMI: the number of the appropriate decisions made / (number of the appropriate decisions made + number of the inappropriate decisions made), using the Game Performance Assessment Instrument (GPAI; Oslin, Mitchell, \& Griffin, 1998).
Operationally, the GPAI was developed in order to assess behaviors associated with game performance, namely those of a tactical-technical nature, also comprising the player's capacity to solve tactical problems, selecting and applying appropriate skills. It is an observation instrument that presents flexibility and can be used to assess the real performance of the players, either through direct or indirect observation (through the subsequent use of video). It does not allow to indicate the level of performance of the players since the performance indices calculated only allow comparisons between players, but it is centered on the dynamic nature of the game, analyzing the final result of the action (effectiveness) and the variables of the execution process directly related to the game action (tactics and techniques; Santos et al., 2016).

Using the 3 formats of SSGs, a tally system addressed the number of appropriate/efficient and inappropriate/ inefficient decisions on each game performance. Every format was recorded. 2 researchers with experience in using the GPAI composed the field team that assessed the players' game performance during the execution. The preparation and training of the field team began with 2 theoretical-practical sessions of 2 hours each, in which real football situations were analyzed using GPAI. After this first phase of training, the pilot study that was carried out to validate the assessment protocols and the experimental game situations also was recorded and used by the field team to have another observational training session and to calculate the intraclass correlation coefficients between all observers and the criterion evaluator.The intraclass correlation coefficients between the independent observer and the criterion evaluator of GPAI total score varied between .767 and .367. Given this result, the observers whose records correlated below.700 were excluded from the principal study.

\section{Statistical Analysis}

First, descriptive statistics of DMI scores were reported as Medians and Means. Second, a Kruskal-Wallis test was performed to analyze the difference in DMI scores across three SSG formats (4vs.4; 4vs.5; 4vs.6). Third, a Man-Whitney U test was individually performed to test differences between DMI between balanced and unbalanced SSG formats. The effect size of the Man-Whitney U test was calculated from the $\mathrm{z}$ value (standardized test statistics) using the following formula: $\mathrm{r}=\mathrm{z} /$ squared root of $\mathrm{N}$, where $\mathrm{N}=$ total numbers of cases. All analyses, except for effect size calculation, were performed using the IBM SPSS Statistics software 
(version 25; SPSS, Inc., Chicago, IL, USA). A level of significance of $5 \%$ was applied in all analyses.

\section{Results}

On the first day, there were no statistical differences in DMI across the three different SSG formats (4vs.4, $\mathrm{n}=8 ; 4$ vs. $5, \mathrm{n}=9 ;$ 4vs.6, $\mathrm{n}=10), \mathrm{c}^{2}(2,26)=4.35, \mathrm{p}=.113$. On the second day, there were statistical differences in DMI across the three different SSG formats $\mathrm{c}^{2}(2$, 26) $=6.46, p=.040$. In the 4vs. 6 format a higher median score $(\mathrm{Med}=.93)$ than in the $4 \mathrm{vs} .4$ format (Med=.73) was recorded, $U=13.0, \mathrm{z}=-2.34, p=.025$, $\mathrm{r}=.57$. Finally, on the third day, there were also statistical differences in DMI across the three different SSG formats $\mathrm{c}^{2}(2,26)=11.87, \mathrm{p}=.003$. In the $4 \mathrm{vs} .6$ format a higher median score $(\mathrm{Med}=1.00)$ than in the $4 \mathrm{vs} .4$ format (Med $=.65)$ was recorded, $\mathrm{U}=5.50, \mathrm{z}=-2.98$, $\mathrm{p}=.003, \mathrm{r}=.72$.

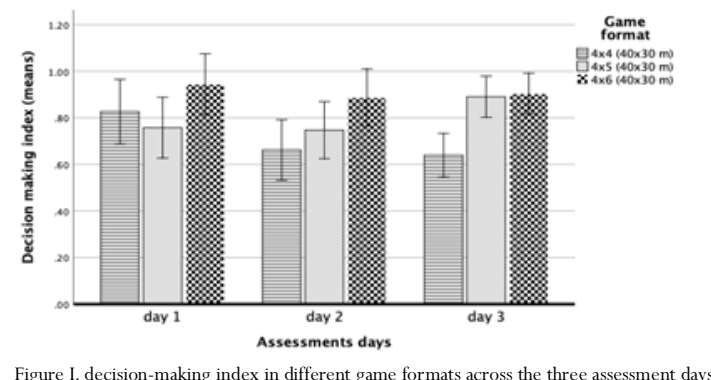

\section{Discussion}

The aim of this study was to assess players' DM in different balanced and unbalanced SSG formats keeping the play area constant. This study provides evidence that in the 4vs. 6 format higher DMI scores than in the 4vs.4 format can be recorded when the play area is kept constant. Looking at the formats understudy and based on the results obtained, we can assume that if the goal is to develop and stimulate DM, when using SSGs, the unbalanced game formats tend to be a better option when compared to balanced formats. An inspection of Figure I suggests that the DMI always tended to be descriptively larger in the $4 \times 6$ format when compared with the other two formats, meaning that the more unbalanced the format is, the probability of making better decisions appears to rise.

There may be a widespread perception that changes in numerical relationships between teams that attack and defend will induce changes in physical behaviors and in the space-time component, namely in individual and collective tactical performance. This is more perceptible on teams with fewer players as they are competing at a numerical disadvantage. Coaches normally resort to permanent inequality to promote or increase the offensive effectiveness of the team with more elements or, on the other side seeking to improve proficiency in terms of positioning and defensive cohesion on the team with the fewest players (Hill-Haas et al., 2011; Travassos et al., 2014; Sousa et al., 2021). Also, studies about imbalances in the number of players in action, indicate that will most likely be induced changes in the diversity, unpredictability and flexibility of tacticaltechnical solutions and consequent decision-making capacity. The structural imbalance enhances the emergence of adaptive behaviours, which provides a new rationale for practice task design (Ric et al., 2016; Canton et al., 2019).

Our findings can have a supportive effect on the coaches' planning of the training sessions, namely for a better understanding of the effects inherent to the manipulation of the number of players to be used in unbalanced and balanced SSG formats. Projecting specific tasks and game contexts using these types of formats, can give an idea of the type of individual behaviors (support actions and efficiency of game skills) and collective (offensive positioning, organization and game principles) behaviors, that occur when there is an adjustment response to possible numerical disadvantages or advantages, with the possibility of transferring this type of behavior to the competition and assisting in creating different game strategies.

Some limitations need to be acknowledged in this study. First, this study included only 12 players from the same team. For future research, we highly recommend the use of larger samples, in addition to the need to modify the sample profile, investigating these formats and constraints in different competitive levels in the youth age-groups, but also for a group of top elite players compared to a group of amateur players. Another important aspect is the need for these studies to be based on a more longitudinal design, to measure variations over a longer period.

On the other hand, some strengths of our study can be underlined. We conducted the same experiment following the same conditions across three consecutive training days to study the stability of the results. Besides, all the assessments followed a well-defined protocol that increases the information quality.

Finally, this study provides evidence about the 
usability of unbalanced SSG formats to improve the DM of the players. We conclude that the use of unbalanced SSG formats in training, may benefit DM development, and therefore may constitute an important factor to be considered in the formation of young football players. These are formats that might have great potential to generate contexts that will induce enhancements or development in the player level. Considering the individual capabilities, it is important to understand the need to create more complex game contexts, for players with good DM capability, or adapting the contexts to a lower complexity, if the level of the practitioner is lower. The key is which type of formats and task manipulation can be used, in order to be assertive in training DM.

Further research should assess tactical and strategic aspects, comprehending the influence that these permanent unbalanced formats and playing conditions imply, using GPS sensors and positioning heatmaps to understand the collective organizational dynamics in terms of offensive and defensive processes.

\section{Acknowledgements}

The authors would like to thank field team (Tomás Quintal; Marcelo Pestana, Romualdo Caldeira; Pedro Freitas; Francisco Fernandes) for technical assistance in data collection and management. We are especially grateful to the younger soccer players who took part in this study for their participation and to the Clube Futebol Andorinha from Santo António, Madeira, for providing us with the sports facilities to carry out the study. Finally, H.S and E.R.G., both belonging to Interactive Technologies Institute (Portugal), acknowledge support from LARSyS - Portuguese national funding agency for science, research and technology (FCT) Pluriannual funding 2020-2023 (Reference: UIDB/50009/2020).

\section{References}

Araujo D, Fonseca C, Davids K, Garganta J, Volossovitch A, Brandao R, Krebs R. The role of ecological constraints on expertise development. Talent Development \& Excellence, 2010; 2(2): 165-179

Araújo, D., Hristovski, R., Seifert, L., Carvalho, J., \&

Davids, K. (2019). Ecological cognition: Expert decision-making behaviour in sport. International Review of Sport and Exercise Psychology, 12(1), 1-25. https://doi.org/10.1080/1750984X.2017.1349826 Baldi, M. F., Silva, C. H. da, Vacari, L., Neto, N. L. N., Santos, R. dos, Pelegrinelli, C. A., \& Pondian, V.
(2016). Análise das ações técnico-táticas em jogos reduzidos no futebol. Arquivos de Ciências da Saúde da UNIPAR, 20(1). https://doi.org/10.25110/ arqsaude.v20i1.2016.5030

Canton, A., Torrents, C., Ric, A., Gonçalves, B., Sampaio, J., \& Hristovski, R. (2019). Effects of temporary numerical imbalances on collective exploratory behavior of young and professional football players. Frontiers in Psychology, 10, 1968. https: / / doi.org/10.3389/fpsyg.2019.01968

Clemente, F., Mendes, R., \& Rocha, R. (2012). Teaching and soccer training: An approach through a tactical perspective. Journal of Sports Science and Technology, 12(1), 57-68.

Clemente, F., Couceiro, M. S., Martins, F. M., and Mendes, R. 2012. «The Usefulness of Small-Sided Games on Soccer Training.» Journal of Physical Education and Sport 12 (1): 93-7.

Correia, V., Araújo, D., Duarte, R., Travassos, B., Passos, P., \&amp; Davids, K. (2012). Changes in practice task constraints shape decision-making behaviours of team games players. Journal of Science and Medicine in Sport, 15(3), 244-249. IF=2.5

Correia, V., Araujo, D., Vilar, L. y Davids, K. (2013). From recording discrete actions to studying continuous goal-directed behaviours in team sports. Journal of Sports Sciences, 31 (5), 546-553. http: / / dx.doi.org/10.1080/02640414.2012.738926

Davids, K., Araújo, D., Correia, V., \& Vilar, L. (2013). How small-sided and conditioned games enhance acquisition of movement and decision-making skills. Exercise and sport sciences reviews. https:// doi.org/10.1097/JES.0b013e318292f3ec

Dellal, A., Owen, A., Wong, D. P., Krustrup, P., van Exsel, M., \& Mallo, J. (2012). Technical and physical demands of small vs. Large sided games in relation to playing position in elite soccer. Human Movement Science, 31(4), 957-969. https: / / doi.org/10.1016/ j.humov.2011.08.013

French, K. E., \& McPherson, S. L. (2004). Development of Expertise in Sport. In M. R. Weiss (Ed.), Developmental sport and exercise psychology:A lifespan perspective (p. 403423). Fitness Information Technology.

Gréhaigne, J.-F., Richard, J.-F., \& Griffin, L. L. (2012). Teaching and learning team sports and games. Routledge. https: / / doi.org/10.4324/ 9780203620700

Hill-Haas, S., Dawson, B., Impellizzeri, M., \& Coutts, J. (2011). Physiology of Small- Sided Games Training in Football: A Systematic Review. Sports Medicine, 
41(3), 199-220. doi: 0112-1642/11/0003-0199

Oslin, J.L., Mitchell, S.A., \& Griffin, L.L. (1998). The game performance assessment instrument (GPAI): development and preliminary validation. Journal of Teaching in Physical Education, 17(2), 231-243.

Menegassi, V. M., Matheus De Oliveira Jaime, Rechenchosky, L., Borges, P. H., Souza, N. M. D., Mendes, C., \& Rinaldi, W. (2020). Quais características diferenciam a vitória, empate e derrota em jogos reduzidos de futebol? Uma análise multidimensional a partir das respostas de jovens atletas (What characteristics differentiate winning, drawing and losing in soccer small-sided games? A multidimensional analysis based on the responses of young athletes).

https: / / doi.org/10.13140/

RG.2.2.14793.16483

Michailidis, Y. 2013. «Small Sided Games in Soccer Training.» Journal of Physical Education and Sport 13 (3): 392-6.

Mills, A., Butt, J., Maynard, I., \& Harwood, C. (2012). Identifying factors perceived to influence the development of elite youth football academy players. Journal of Sports Sciences, 30(15), 1593-1604. https: / / doi.org/10.1080/02640414.2012.710753

Passos, P., Araújo, D., Davids, K., \& Shuttleworth, R. (2008). Manipulating constraints to train decision making in rugby union. Int J Sports Sci Coach 2008;3(1):12540. https: / /doi.org/10.1260/174795408784089432

Ric, A., Hristovski, R., Gonçalves, B., Torres, L., Sampaio, J., \& Torrents, C. (2016). Timescales for exploratory tactical behaviour in football small-sided games. Journal of Sports Sciences, 34(18), 1723-1730. https: / /doi.org/10.1080/02640414.2015.1136068

Santos, R. B. dos, Mendes, R. S., Dias, G. N. F., \& Coelho e Silva, M. J. C. (2016). Avaliação da performance em jogos desportivos - GPAI e TSAP. Conexões, 14(2), 137. https://doi.org/10.20396/ conex.v14i2.86466042

Sarmento, H., Clemente, F. M., Harper, L. D., Costa, I. T. da, Owen, A., \& Figueiredo, A. J. (2018). Small sided games in soccer - a systematic review. International Journal of Performance Analysis in Sport, 18(5), 693-749. https://doi.org/10.1080/ 24748668.2018.1517288

Sgrò, F., Bracco, S., Pignato, S., \& Lipoma, M. (2018). Small-Sided Games and Technical Skills in Soccer Training: Systematic Review and Implications for Sport and Physical Education Practitioners. Journal of Sports Science 6 (2018) 9-19. doi: 10.17265/ 2332-7839/2018.01.002

Sousa, H. J., Gouveia, É. R., Marques, A., Sarmento,
H., Caldeira, R., Freitas, R., Lopes, H., Prudente, J., \& Ihle, A. (2021). The effect of balanced and unbalanced soccer small-sided games on the rating of perceived exertion in youth players (El efecto de los partidos reducidos de fútbol equilibrados y desequilibrados em la calificación del esfuerzo percebido em los jugadores j. Retos, 41, 440-446. https:// doi.org/10.47197/retos.v0i41.83091

Torreblanca-Martínez, V., Cordero-Ojeda, R., \& González-Jurado, J. A. (2018). Análisis de variables condicionales y técnico-tácticas mediante juegos reducidos en futbolistas semiprofesionales (Analysis of physical and technical-tactical demands through small-sided games in semi-professional football players). Desafios, (35), 87-90. https://doi.org/ 10.47197/retos.v0i35.59448.

Travassos, B., Araujo, D., Davids, K., Vilar, L., Esteves, P., \& Correia, V. (2012). Informational constraints shape emergent functional behaviors during performance of interceptive actions in team sports. Psychology of Sport \& Exercise, 13(2), 216-223. doi: 10.1016/j.psychsport.2011.11.009

Travassos, B., Vilar, L., Araújo, D., \& McGarry,T. (2014). Tactical performance changes with equal vs unequal numbers of players in small-sided football games. International Journal of Performance Analysis in Sport, 14(2), 594-605. https://doi.org/10.1080/ 24748668.2014.11868745

Turner, A., \& Martinek, T. J. (1995). Teaching for understanding: A model for improving decision making during game play. Quest, 47(1), 44 63.https: / /doi.org/10.1080/00336297.1995.10484144

Williams AM, Ford PR. 2013. 'Game intelligence': anticipation and decision making. In: Williams AM, editor. Science and soccer: developing elite performers. 3rd ed. London (UK): Routledge; p. 105-121.

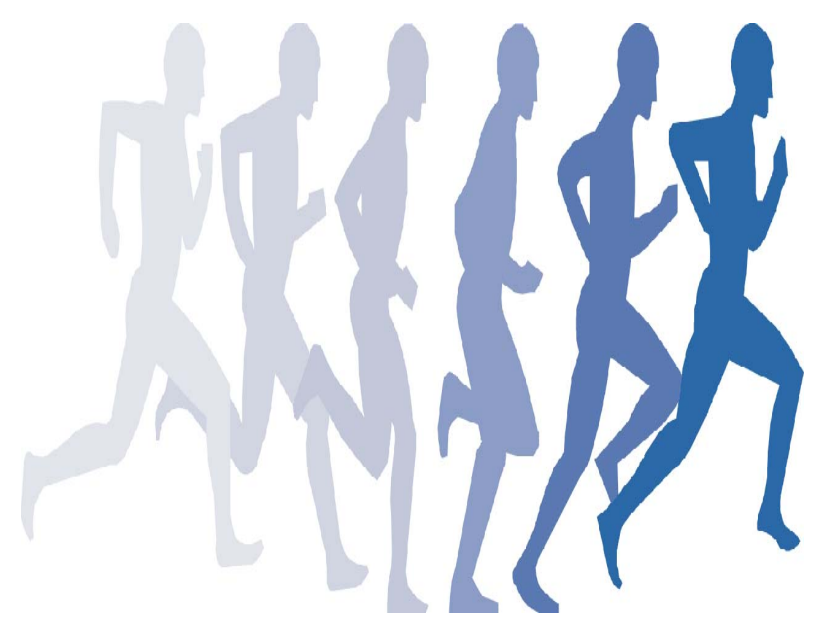

